over the gexual function has been proved by the same anthor in the case of a fox-terrier bitch, in which oestrum was observed several times, and the ovary. was found to contain large Graafian follicles 370 days after the grafting had been performed.

Evidence is not lacking, moreover, that grafting may be successfully accomplished in the human subject. Franklin H. Martin ${ }^{4}$ has published the histories of six patients who continued to menstruate after transplantation of the ovaries; and Davidson ${ }^{5}$ has recently recorded before the Edinburgh Obstetrical Society the case of a patient who began to menstruate thrc 2 montlis after the operation and has continued to do so since without either local or pelvic pain. To those interested in the subject the valuable monograph of Sauvé, ${ }^{6}$ published in 1909, may be recommended as containing a full account of the history and earlier experiments in this field of investigation.

\section{"Seedling" Grafts.}

In almost all cases recorded in the literature, with the exception of those of Scott Carmichael, the graft has consisted of the whole or a very large portion of the ovary. I am inclined to think that much greater success will attend the use of small portions of tissue, as is done in the case of the thyroid and other glandular tissues. Because the ovary is a small gland, it does not necessarily follow that it can be lifted bodily and placed in a new position. The vitality of the tissue is much more likely to be maintained if "seedling" grafts are made. Furthermore, the chances of success are proportionately increased by the number of grafts made.

\section{Site of Implantation.}

As regards the site of implantation, my own preference is for the rectus muscle and subperitoneal tissue. The reasons for this are as follows: In the first place, a good vascular supply is assured; secondly, tbe grafting may be most easily accomplished in this position, and involves very little increase in the time of the operation; lastly, should the graft require removal at any time, either from late suppuration or the development of a neoplasm, it may be reached easily and without the risk of opening the peritoneum. Further observation, of course, must show in what proportion of cases it is necessary to interfere at a later period for morbid changes occurring in the graft. So far as published records point, this eventuality is extremely slight.

\section{Indications.}

The indications for ovarian grafting will naturally be limited. One of the most important uses for the operation is indicated in the case recorded earlier in this papernamely, as a conservative measure when it is necessary in a young woman to remove both uterine appendages for o'd-standing inflammatory disease without having to sacrifice the uterus.

Opinions will undoubtedly differ as to the proportion of cases in which this is possible. Undoubtedly a large number of cases occur where the uterus has to be removed with the appendages. Nevertheless, it is remarkable sometimes how rapidly and completely adhesions disappear when the inflammatory foci in the tubes and ovaries are removed. Furthermore, observations that I have recently made upon the bacteriology of the uterus in cases of chronic pyosalpinx have led me to believe that the endometrium is, as a rule, sterile, and therefore $I$ have no compunction in leaving the uterus in such cases, especially when it may be possible to graft ovarian tissue into the abdominal wall. Another indication which I put forward as a suggestion is the possibility of transplanting fragments of ovarian tissue in cases of severe dysmenorrhoea. Instances of most intense menstrual pain un doubtedly occur where the source of discomfort lies, not in the uterus, but in the ovaries. Curetting and drugs rarely cure such patients, and if an examination is conducted during the height of the attack the ovaries can frequently be palpated as extremely tender bodies occupying the posterior quadrants of the pelvis. In more than one case oöphorectomy has been and is still practieed for this con dition, and I know of instances where panhysterectomy has been performed. A cure is undoubtedly effected thus, but may not it be possible to bring about the same result withont unsexing the patient, by sukstituting ovarian grafting? Many of these patients are young women, and it appears more rational to attempt a cure by conservative measures rather than acknowledge the failure of our art by subjecting the patient to a radical operation in which she loses those very organs which produce the hormoncs characteristic of her sex.

\section{Conclusions.}

In conclusion may be summarized those points which I regard as essential to the success of a grafting operation :

1. Absolute asepticity and the avoidance of strong antiseptics which would destroy the vitality of the tissues. The apparent contradiction to this maxim in the case of chronic pyosalpinx and salpingo-oöphoritis is met by the fact that the pus in such cases is usually sterile, and the tissues may be treated as surgically " clean."

2. The employment of minute or " seedling" grafts.

3. The presence of a good vascular supply in the tissue used as the bed for the graft. Muscle is entirely satis. factory for the purpose.

4. The ovarian tissue should be left in contact with the body fluids within the peritoneal cavity until it is required for the purposes of the grafts. In the case recorded in this paper the ovary was placed in Douglas's pouch until the time arrived for closure of the abdominal wound.

The object of this communication will have been attained if it serves to draw attention to the investiga. tions of the various workers in this field throughout the world, and to the possibilities that underlie the wider adoption of the principle. Laboratory researches have already demonstrated the success that may be obtained, and it now remains for the gynaecological surgeon to apply these results, to glean fresh details from the afterresults of his operations, and to formulate indications for the future employment of this branch of our art.

\section{REFFRENCFS}

${ }^{1}$ Scott Carmichael, Eainburgh Medical Journal, February, 1909 2 Higuchi, A rchiv für Gynakol., vol. xci, Pt. I, 1) 214. ${ }^{3}$ Nattruss, Reports Physiological Laboratory, University of Melbourne, June, 1910. 4 Franklin H. Martin, Surgery, Gynaecology, and Obstetrics, July, 1911. 5 Davidson, Trans. Edinburgh Obstetrical Society, 1912. 'Sauvé, Les greffes ovariennes, Paris, G. Steinheil, editeur, 1909; Bulletins de la Sociéte Anat. de Paris, November, 1907. 7 Cassalis,
Journal of Obstetrics and Gynaecology of British Empire, vol. xv, 325 .

\section{NOTES OF A SUPPOSED CASE OF PELLAGRA.} BY

ROBERT REID, M.D.,

PHYSICIAN TO THE:THRONE HOSPITALS, BELFAST,

AND

WILLIAM CALWELL, M.D.,

PHYSICIAN TO THE ROYAL VICTORIA hosPital; CONSULTING PHYSICIAN TO THE THRONE CONSUMPTIVE HOSPITAL, BELFAST.

The patient, James $K$., is a farmer, aged 66 , residing some five or six miles from Belfast. He has generally been healthy, but has been liable all his life to frontal headaches, lasting one to two days, with relief after vomiting. For the past three or four years he has consulted Dr. Reid during spring and autumn for a dermatitis resembling eczema on the back of his hands and on the chin and parts about the mouth. This spring and summer the condition became much worse, especially on the hands; the back of the hand down to the finger-tips became brawny and much darker in colour; they had, he said, been black since May, and the discoloration had been most marked during the fortnight before he came under observation; the palms were free; there was desquamation at intervals of the skin of the nose and chest, and Dr. Reid suspected pellagra. The patient was seen by Dr. Calwell on July 15th, 1913, and subsequently in hospital in his skin clinic.

The patient's intelligence is good, but his memory had recently failed and he was apt to worry unduly about trifles; he was rather feeble in bodily health; althougl, always spare, he had recently become thinner and was somewhat nervous; his gait was shnffling, his steps short, and his movements stiff; the right pupil was smaller than the left, and both reacted to light; there was no rigidity; the knee-jerk was feebly marked in the right leg and absent in the left. The back of the havds was darkish brown, as if stained with walnut-juice, and where 
the superficial cuticle was peeling the skin was red and irritable; there was some slight darkish discoloration on the red eczematous parts of the cheeks, forehead, and front of the chest. His lips smarted, and he complained of soreness at the angles of the mouth; he said his sight was failing, and that during the last month or so there had been occasional diplopia; lately there had been somo tingling in his feet and slight staggering; slight irregularity of the heart (extrasystoles) and a faint mitral systolic murmur without hvpertrophy were noted.

He stated that a stream of water from some marsliy ground had been piped into his yard and had been continually used for farming purposes. No other member of the family has been affected in the same way.

The affection is certainly peculiar, and does not tally with any of the common forms of skin or nervous affections. The resemblance to the verbal description and to the illustrations of pellagra in the JournaL is close.

EIGHTY-FIRST ANNUAL MEETING OF THE

\section{通ritizh Attediral Aszaniation.}

Held in Brighton on July 23rd, 24th, and 25th.

PROCEEDINGS OF SECTIONS.

\section{SECTION OF \\ DISEASES OF CHILDREN, INCLUDING}

ORTHOPAEDICS.

G. F. Still, M.D., F.R.C.P., President.

\section{DISCUSSION ON}

\section{AFFECTIONS OF THE HEART IN CHILDHOOD.}

\section{OPENING PAPERS.}

\section{I.-F. J. Poynton, M.D., F.R.C.P.,}

Serior Physician to Out-patients, University College Hospital, and the Great Ormond Street Hospital for Sick Children.

$I_{N}$ order to avoid drifting in this many-sided subject $I$ have taken as the central thread of my remarks the prevention of heart disease in the young.

Such an undertaking as the prevention of heart disease requires a wide appreciation of the many factors that combine to make heart affections in the young a very serious problem in this country, and this leaves an open field for the many speakers who will, I hope, join in the discussion to cover ground I cannot reach, to add their valuable experiences, and to make suggestions which will be of real service to the children with whom we are concerned.

Now, it is clear that this question of prevention must be largely influenced by the views that each of us may hold upon the chief cause of heart disease in the young. Convinced as I am that rheumatism is an infective process, it follows that for me the great factor in the causation of leart disease in childhood is an infective process of some kind or another, and the most frequent of these the rheumatic.

Then we come to a point upon which an expression of opinion will be of value, and that is upon the extent to which agencies of a non-infective nature-such, for example, as overstrain and nervous disorders-take a part in the production of heart disease in the young.

This, if we are to be practical, is not a simple problem, for though we may readily admit that it may be most difficult to overstrain a young and sound heart, we have to meet the question under a somewhat different aspect. How frequently, I would put it, do you belicve from your experiences does overstrain of the heart become a prominent factor by determining bad symptoms in children who are thought to be healthy, but who have either recently suffered from some illness, such as, for example, a mild influenza, or have inherited, as I believe some do inherit, a heart of deficient reserve power?

I agree with the view that pure cardiac overstrain is unusual, but when we consider the large schools it would seem quite possible that a boy may strain his heart when he has been attacked by some infection of so slight an apparent gravity as scarcely to have attracted attention. Then, again, thers aro boys of a nervous temperament who probably by virtue of this very temperament may excel in games of skill over their larger and duller rivals, and also are sometimes the victims of a condition termed by some "neurasthenia," which, whaterer we call it, shows itself in cardiac palpitation, nervousness, shortness of breath, and other signs of a breakdown.

In the consideration of heart-strain it appears to me that a good deal too much stress has been laid upon the muscle of the heart as opposed to the cardiac nerves, for in diseases of the heart this nervous element is of great importance, and I always think of the cardiac muscle and cardiac nerves as merging insensibly into one another.

The point I am wishing to make here is this: Granted that pure overstrain of a sound young heart is very rare, to what extent does this Section think that physical and mental overstrain takes part in producing cardiac dilatation and functional symptoms in children as we meet with them in everyday life.

Among conditions clearly not infective in nature I would mention the association of remarkable disturbances of rhythm with the occurrence of convulsions. The dis. turbances have lasted in some instances for months and even for two years after the last recorded fit. An electrocardiogram from an infant of 2 years, kindly taken for me by Dr. T. Lewis, shows an irregularity due to auricular extrasystole which had, to my personal knowledge, been present for eighteen months. The infant at 3 months had suffered from convulsions, but since that time had never had an attack. During the first six months of my observations the irregularity had been much more striking than at the time the tracing was taken, and no remedies, whether for the digestion or for the heart, appeared to me to have any influence upon it. About eight months after I first saw the child a systolic mitral murmur became audible, but at no time could I find any symptoms pointing to cardiac weakness. Up to the present the irregularity continued, and the case remains to me a problem.

I am not prepared to say that the convulsions have any real connexion with these irregularities of the heart, but put these cases before you in the hope of gaining further information upon them.

Anaemia, as we know, often owns an infective cause; and it is an element, I think, of considerable importance in aggravating the course and symptoms of organic heart disease. Hyperthyroidism at and about puberty is another condition of interest, but when the whole field is surveved it secms to me that the chief factor in the heart disease of childhood is an infection of some kind or another. With congenital heart disease I cannot deal in this introduction.

A study of the morbid anatomy and microscopy of organic heart disease, coupled with experimental studies, although they involve details ill suited for occasions such as these, aro valuable methods for obtaining a clear picture of the actual processes; and, if we wish to prevent heart discase, it is essential that we pay close attention to such studies, in order to realize what is preventable and what can only be palliated.

A vegetation may form on the cardiac valve of a rabbit in three days, and definite myocardial changes appear in the same short time. In five weeks a pericardium may become generally adherent in a rabbit, and in three months in a child about the same degree of resolution may be obtained.

The focal lesions in the myocardium that result from rheumatism form the basis of new investigations with the polygraph and electrocardiograph, and we hope that in the future these may bring during life additional evidenco upon the relative importance of myocardial affections in rheumatism, just as the experimental studies and pathological studies add an accuracy to our linowledge of the character of these myocardial lesions. The bearing of these latter studies upon prevention is very clear, for they show that when infective processes aro highly destructive or very persistent, scar tissue must form if there is to be recovery, and then we are unable to undo the lyarm, and can at best only attempt at preventing greater damage or palliate the harm that has been already done.

Our clinical knowledge tells us plainly that when a certain degree of damage has becn done the child must be 